Journal of Social Sciences 5 (4): 386-389, 2009

ISSN 1549-3652

(C) 2009 Science Publications

\title{
Developing of Stage Ornament Creation for Enhancing Economic Value Added in Isan Community
}

\author{
${ }^{1}$ Pattamawadee Chansuwan, ${ }^{2}$ Suphanni Luaboonchu and ${ }^{3}$ Terdchai Pantachi \\ ${ }^{1}$ Faculty of Fine and Applied Arts, Mahasarakham University, Khamriang Campus, \\ Khantharawichai Mahasarakham, 44150, Thailand \\ ${ }^{2}$ College of Music, Mahasarakham University, Khamriang Campus, \\ Khantharawichai Mahasarakham, 44150, Thailand \\ ${ }^{3}$ Yasothon Pittayakhom School, Cheangsanit Road, Tambon Nai Mueaneg, \\ Amphoe Mueang, Yasothon Province 35000, Thailand
}

\begin{abstract}
Problem statement: Several communities in northeast Thailand are creative and productive sources of stage ornaments but they cannot expand their markets according to the changes of customer requirements. Approach: This research aimed to investigate 3 point. (1) To investigate the background of stage ornament creation in Isan (northeast) community in the past. (2) To investigate the situation and difficulties of stage ornament creation on Isan community of present. (3) To investigate the development of stage ornament creation for enhancing economic value added in Isan community. A qualitative research was used for this research. The data were collected by a literature survey together with a survey and observation, an interview and a focus group in the field. The sample was 20 key informant, 12 ornament distributors, 28 ornament users and 20 persons consisted of the public, students and scholars. The research instruments were a survey form, and observation form, a structured-interview form and a non-structured interview form. The data were analyzed and presented by means of a descriptive analysis. Results: Results revealed that the background of stage ornament creation in Isan (northeast Thailand) community in the past began with a family or relative group production. In 1997 some stage ornament productive families sent their members to train in new production and designs at Thepakorn Temple, Bangkok; the stage ornament shops have widely established in northeast Thailand since then. At present, the difficulties of stage ornament creation were a lack, of low-cost materials sources, a lack of loan raising sources, a lack of skilled workers, lack of public relations and because of each production group is a small scale so it can hold only northeastern markets. According to the difficulties which affected stage ornament creation each production group should develop both creation and production such as setting creation and production standards, increasing productivity, expending customer groups, searching for loan raising sources. Conclusion/Recommendations: Stage ornament creation is an indigenous which handed down from generations to generations. At present, the changes of customer requirements are different from the past, thus each of creation groups should develop both creative and productive process for enhancing economic value added according to these changes. The research on the ways to enhancing economic value added of stage ornaments should operate seriously in order to encourage the appreciation of this cultural occupation. The concerned organizations both state and private sectors should support this occupation in several ways such as supporting loan raising, supporting productive knowledge, supporting low cost materials, supporting market-places.
\end{abstract}

Key words: Developing, stage ornament, creation, economic value added

\section{INTRODUCTION}

Stage ornament is the ornament which the performer wears while performs on the stage in order to enhance the beauty and characteristic of performer. A set of stage ornaments consists of head ornaments, body ornaments, arm ornaments and leg ornaments including face-make up and hair-dressing ${ }^{[1]}$. The function of stage ornaments is to identify the characteristic and status of the performer, moreover it evinces cultural period,

Corresponding Author: Pattamawadee Chansuwan, Faculty of Fine and Applied Arts, Mahasarakham University, Khamriang Campus, Khantharawichai Mahasarakham, 44150, Thailand 


\section{J. Social Sci., 5 (4): 386-389, 2009}

situation, the social position of the performer and enhances the beauty of performer movement.

Especially, head ornaments are very important because ancient-Thai people believe that quardian spirit lives in one's head or live in the hair that grows in a whorl on the top of one's head. Thus they like to have long hair and put their hair up in a bun on the top of their heads. They gather up their hair with topknot ornament which decorate with flowers or gems, latterly topknot ornament like these are developed to coronets or crowns which used for identifying the insignia of rank. At present, stage ornament such as head ornaments, body ornaments are developed in their forms according to a kind of performance. This development is not only for a dramatic art performance but also for others such as a musical folk drama, a northeastern-Thai folksinger and a background-dancer performance. As above-mentioned, stage ornaments are made from several materials such as a black-laquer gilt plate inlaid with gems, a gilt plate inlaid with gems, a gilt plate inlaid with gems. Both types of ornaments are rather expensive. But stage ornaments like these which made from artificial leather are rather cheap. Phahurat, Bangkok is the centre of stage ornaments; this centre orders them from the producers in central part of Thailand so their cost are rather expensive.

At present, the requirement of stage ornaments is on the increase. Because the educational system institutes dramatic arts in the curriculum of the basic education, dramatic arts in the curriculum of the basic education, dramatic arts and performance arts are widely instructed in higher educational institutes, each of educational institutes usually arranges a dramatic art competition, entertainment such as a northeastern-Thai folksinger performance prefer using black-laquer gilt ornaments inlaid with gems to using gilt ornaments inlaid with gems and there are a lot of stage ornament shops in Isan (northeast) community that support this requirement. Thus, the occupation of stage ornament production has appeared since then. But this occupation still lacks the productive experts, because it needs some patient persons who can cling on a delicate production for a long time. In the past, ancient people who mastered this field did not hand down to the public but only handed down to the members of family or relatives so it was un appeared in case of nobody carried on it.

In order to reduce a productive cost and sell stage ornament at an appropriate rate, several communities in the provinces of Si Sa Ket, Buri Ram, Roi Et and Maha Sarakham have established the groups of stage ornament production and produced these products for serving the requirements of customers in northeast Thailand. Stage ornaments that were produced in northeast Thailand could divide into 2 items, namely the stage ornament items which imitated from original designs and the applied or new creation items. Some groups of stage ornament creation developed their products to O-TOP (One Tambon (Subdistrict)-One Product) under government support.

\section{MATERIALS AND METHODS}

Research areas: Amphoe Mueang (Mueang Districts) of Si Sa Ket, Buri Ram, Roi Et and N Maha Sarakham Province.

Research methods: The sample was 20 key informants, 12 ornament distributors, 28 ornament users and 20 persons consisted of the public, students and scholars. The research instruments were a survey form an observation form, a structured-interview form and a non-structured interview form. The data were analyzed and presented by means of a descriptive analysis.

\section{RESULTS}

According to the background of stage ornament creation in Isan (northeast Thailand) community in the past, it began with a family and relative group production. 4 types of stage ornaments were produced such as head ornaments, body ornaments, arm ornaments and leg ornaments. In order to create new designs of stage ornaments, some stage productive families sent their family members to train in stage ornament production and creation at Thepakorn Temple, Bangkok in 1997. Afterwards, they have applied trained knowledge to stage ornament production and established their shops since then.

Up to the present, these shops have carried on their business more than 10 years and still been small businesses. Each of stage ornament creation groups gained a sufficient income as a reason of the majority of customers were in northeastern provinces. The difficulties were a lack of low-cost materials sources, a lack of loan raising sources, a lack of skilled workers, a lack of public relations and a limit of stage ornament markets.

According to the difficulties that mentioned above each of them should develop both creation and production of stage ornaments such as setting creation and production standards, increasing productivity, searching for loan raising sources, expanding customer groups, developing to community economy, making marketing plan and advertising. These ways can enhance economic value added of stage ornaments and also enhance earnings of business and community. 


\section{J. Social Sci., 5 (4): 386-389, 2009}

\section{DISCUSSION}

The researcher would like to discuss the research results according to research purposes as follows:

- The background of stage ornament creation in Isan (northeast Thailand) community in the past revealed that it began with a family and relative group production. A set of stage ornament consisted of head ornaments, body ornaments arm ornaments and leg ornaments. This was consistent with the research of Pannaengphetch ${ }^{[2]}$ Acient-Thai people wore ornaments for enhancing their beauty and identifying their social positions, especially head ornaments such as coronets and crowns were symbols which identified the insignia of ranks. This was consistent with the research of Sumit ${ }^{[3]}$, mentioned that performers have used stage ornaments for a dramatic art performance since Ayudthya period and each of stage ornaments has identified the insignia of ranks through each performer. Normally the ornaments which made of gold were use for the Royal Family. Silver ornaments were use for the nobility and copper ornaments were use for the public. Wattana ${ }^{[4]}$ mentioned that forms of traditional ornaments were changed into modern forms which decorated with a lot of gems in the region of King Rama V. The majority of stage ornaments were produced by a technique of black-lacquer and gilt decoration and metal welding that was consistent with the research of Sawanya ${ }^{[5]}$ that studied about stage ornaments of a play of Cho Phaya Si Thammarat and mentioned concerning productive technique that also used the same technique. The businesses of stage ornament creation and production in Isan (northeast Thailand) community have widely established since 1997 by a group of producers who were trained in stage ornament creation and production at Thepakorn Temple, Bangkok

- The situation and difficulties of stage ornament creation in Isan (northeast Thailand) community at present revealed that each of stage ornament creation groups gained a sufficient income as a reason of the majority of customers were in northeastern province so it could not expand its business scale. Sequentially, the difficulties were a lack of low-cost materials sources, a lack of loan raising sources, a lack of skilled workers, a lack of public relations and a limit of stage ornament markets. This was consistent with the research of Myer $^{[6]}$, mentioned that the difficulties of productive process were a lack of materials, a lack of productive standards, a lack of market-places, a lack of capital, a lack of customers, a lack of public relations and a lack of marketing plan. Thus, each of them must develop both creative and productive standards according to the changes of customer requirements

- The development of stage ornament creation for enhancing economic value added in Isan (northeast Thailand) community revealed that according to the changes of customer requirements each of stage ornament creation groups should develop both creative and productive processes such as setting creative and productive standards, increasing productivity, searching for loan raising sources, expanding customer groups, developing to community economy, making marketing plan and advertising

In order to set creative and productive standard, each of stage ornament creation groups should hand down idea and technique concerning stage ornament creation to new generation. This was consistent with the cultural history theory of Franz Boas, mentioned that cultural identity came from a freedom creation ${ }^{[7]}$ and also was consistent with the aesthetic theory of Plato, mentioned that real beauty was in one's imagination ${ }^{[8]}$. In order to increase productivity, each of stage ornament creation groups should hand down this knowledge to people in community, personated them to appreciate and make a living with this occupation. By this way the stage ornament creation groups should have enough skilled workers for increasing productivity.

Concerned organizations both state and private sectors should support loan raising for stage ornament creation groups in order to expand their business scales. In order to expand customer groups, each of stage ornament creation groups should search for new market-places such as Bangkok, the provinces around Bangkok and other provinces.

In order to develop this occupation to community economy, increasing productivity, increasing skilled workers, expanding market-places and enhancing economic value added were necessary. When this business gained a large amount of earnings the people would also interest in this business.

Marketing plan and advertising could enhance all of business growth. By these ways, stage ornament creation business could expand its scale, expand market-places and expand customer groups. 


\section{CONCLUSION}

Stage ornament creation is an indigenous which handed down from generations to generations. At present, the changes of customer requirements are different from the past, thus each of creation groups should develop both creative and productive process for enhancing economic value added according to these changes. The research on the ways to enhancing economic value added of stage ornaments should operate seriously in order to encourage the appreciation of this cultural occupation. The concerned organizations both state and private sectors should support this occupation in several ways such as supporting loan raising, supporting productive knowledge, supporting low cost materials, supporting market-places.

\section{ACKNOWLEDGEMENT}

The researchers wish to declare the deepest sense of thankfulness to the Research Institute of Northeast Art and Culture, Mahasarakham University. We also wish to express our thankful gratitude to any people from Muang District of Si Sa Ket, Buri Ram, Roi Et and Maha Sarakham Province.

\section{REFERENCES}

1. Wirunrak, S., 2000. Dance Periscope. 1st Edn., Chulalongkorn University, Bangkok, ISBN: 9743337849, pp: 300.
2. Pannengphet, S., 1995. A Study of the Development of Thai Puppet: The Folk Media in Western Thailand. UCOM Group, Bangkok, ISBN: 9748922464, pp: 361.

3. Sumit, T., 1998. Thai Dramatic Arts: Dramatic Arts for Primary Teachers-Higher Teachers. Odien Stor, Bangkok, ISBN: 9742775591, pp: 51.

4. Wattana, J., 2002. Ornament Design. Chulalongkorn University, Bangkok, ISBN: 9741315368, pp: 16-19.

5. Sawanya, W., 1996. Nakhon Si Thammarat Female Court Dance. Chulalongkorn University, Bangkok, ISBN: 974-635-441-8, pp: 80-95.

6. Myers, J.E., 1981. Instructor Manual. 3rd Edn., Holt, Rinehart and Winston, New York, ISBN: 9780030578830.

7. Somsak, S., 2001. A Study of Society and Culture: Concepts Methodologies and Theories. Khon Kaen University, Khon Kaen, ISBN: 9742768455 , pp: 2-3.

8. Suansri, S., 1991. Aesthetic of Visual Arts. Odien Store, Bangkok, ISBN: 9742768455, pp: 2-3. 